\title{
Selection of Logistics Service Provider Based on Fuzzy Comprehensive Evaluation
}

\author{
Zhi-Wang Qian, Yu-Feng Shi, Xiao-Lei Du \\ Shanghai University of Medicine \& Health Sciences, Shanghai, PR. China \\ E-mail: qianzw@sumhs.edu.cn, shiyf@sumhs.edu.cn, duxl@sumhs.edu.cn
}

\begin{abstract}
Fuzzy comprehensive evaluation method makes qualitative evaluation into quantitative evaluation based on the membership degree theory of fuzzy mathematics. The fuzzy comprehensive evaluation model is first established; and then the selection evaluation index set of logistics service provider is designed. Finally, the algorithm and process of the fuzzy comprehensive evaluation method in the selection of logistics service providers is expounded by an example. The results show that the fuzzy comprehensive evaluation method is clear, reasonable and scientific. It can solve the problem of fuzzy and difficult to quantify, and it is suitable for solving uncertain problems.
\end{abstract}

Keywords-Fuzzy comprehensive evaluation method; Logistics service provider; Iindex set; Membership matrix; Weight

\section{INTRODUCTION}

The key of logistics outsourcing success depends on the ability of firms to choose suitable logistics service providers. At present, the choice of logistics service providers different in many ways, the qualitative methods, such as intuitive judgment method, bidding, negotiation method; quantitative methods, such as linear weighted method, hierarchical analysis hierarchy process (AHP), mathematical programming method and statistical/probabilistic method, activity-based costing (ABC) and data envelopment analysis (DEA) method, approximate ideal solution ranking method (TOPSIS), fuzzy comprehensive evaluation method, genetic algorithm, neural network and so on. As the selection criteria of logistics service provider are multi-level and multi index features, and most evaluation indicators are qualitative indicators, the attribute measure is uncertain. Therefore, the evaluation of logistics service providers has a certain ambiguity. And fuzzy comprehensive evaluation method is comprehensive evaluation of a qualitative and quantitative combined the organic combination of the fuzzy set theory and AHP (analytic hierarchy process) method.

\section{FUZZY COMPREHENSIVE EVALUATION MODEL}

\section{A. Evaluation Index}

The main index set is defined as $U=\left\{U_{1}, U_{2}, \cdots, U_{n}\right\}$; the sub factor layer index set is defined as $U_{k}=\left\{U_{k 1}, U_{k 2}, \cdots, U_{k n}\right\}$. And the evaluation grade is divided into m class, $V=\left\{v_{1}, v_{2}, \cdots, v_{m}\right\}$.

\section{B. Membership Matrix}

Using Delphi method, the single factor in $U_{i}(i=1,2, \cdots, 4)$ is evaluated by experts group composed of several experts. In this way, we get the membership vector of evaluation set $\mathrm{V}, R_{i j}=\left(r_{i j 1}, r_{i j 2}, \cdots, r_{i j m}\right)$. In this function $r_{i j h}=v_{i j h} / p$; and $\mathrm{P}$ is the total number of participating experts; $v_{i j h}$ is the number of experts who think $U_{i j}$ belong to $v h$. The membership matrix is as follows:

$$
R_{i}=\left[\begin{array}{l}
r_{i 1} \\
r_{i 2} \\
\vdots \\
r_{i j}
\end{array}\right]=\left[\begin{array}{l}
r_{i 11}, r_{i 12}, \cdots, r_{i 1 m} \\
r_{i 21}, r_{i 22}, \cdots, r_{i 2 m} \\
\vdots \\
r_{i j 1}, r_{i j 2}, \cdots, r_{i j m}
\end{array}\right]
$$

\section{The Weight of Indicators}

As the important degree of different factors on the evaluation of different goals are different, it is necessary to evaluate the relative importance of different factors and give them the corresponding weights. There are a lot of weight determination methods, this paper uses AHP to calculate the main factors in index set $\mathrm{U}$, the corresponding weight set is $\mathrm{A}=\left(A_{1}, A_{2}, \ldots, A_{n}\right)$.

Analytic hierarchy process method (AHP) is proposed by T.L Saaty in the late 1970s, the operational research experts. The characteristics of this method is using less quantitative information to make the evaluation of the thinking process digitalized after thorough analysis on the essence of complex decision-making problem, factors and its internal relations. It provides a simple method for evaluation of the multi-objective and multi criteria or no structural properties complex problems.

The key step to determine the index weight is to construct the judgment matrix. Constructing the judgment matrix is to evaluate index repeatedly. That is to say that which indicators have bigger influence on the indicators of upper level can be illustrated by a certain number.

In this way, through the comparison of the two indicators at all levels, we can get the judgment matrix of indicators. With the judgment matrix, the relative weight of each index is calculated to get the eigenvalue of judgment matrix. Usually the approximate eigenvalues are calculated as the weight value. 
- $\quad$ The matrix A is normalized by column

$$
b_{i j}=\frac{a_{i j}}{\sum_{i=1}^{n} a_{i j}}(i, j=1,2, \ldots, n)
$$

- $\quad$ Each row is calculated normally in the judgment matrix, i.e.

$$
w_{i}=\sum_{j=1}^{i} b_{i j}
$$

- Regularize the vector to get the weight vector:

$$
\vec{w}_{i}=\frac{w_{i}}{\sum_{i=1}^{n} w_{i}}(i, j=1,2, \ldots, n)
$$

- $\quad$ The largest eigenvalue of the matrix:

$$
\lambda_{\text {man }}=\sum_{i=1}^{n} \frac{L_{A} \overrightarrow{w_{i} j}}{n\left(\overline{\left.w_{i}\right)}\right.}
$$

The consistency test is needed to get the characteristic value of the matrix. $\lambda_{\operatorname{man}}$ is the largest eigenvalue in the matrix of $\mathrm{A}$. When $\mathrm{A}$ is consistent, the ranking vector $\omega$ can be accurately obtained. However, A is not consistent generally. When $\lambda_{\text {man }}$ is close to $\mathrm{n}, \varpi$ is close to the right sort $\omega$. That is to say, the more reliable the judgments are made, the closer agreement we get and the more accurate the importance ranking vector is.

Therefore, in order to examine the evaluation of reliability or consistency, we establish a consistency index. The difference between the largest eigenvalue of the matrix $\mathrm{A}$ and $\mathrm{n}$ is divided by $\mathrm{n}-1$, and the ratio is used as a measure of judgment matrix of deviation from the consistency of the index. So we have $C I=\frac{\lambda_{\max }-n}{n-1}$.

Generally speaking, the difficulty of judgment consistency increases with the increase of the order of the judgment matrix. In order to measure consistency of judgment matrix with different order, the concept of relative consistency is necessary. Therefore, we introduce average uniformly random index RI of judgment matrix, as shown in Table 1.

TABLE I. AVERAGE RANDOM CONSISTENCY INDEX

\begin{tabular}{|c|l|l|l|l|l|l|l|l|l|l|l|}
\hline order & 3 & 4 & 5 & 6 & 7 & 8 & 9 & 10 & 11 & 12 & 13 \\
\hline RI & 0.52 & 0.89 & 1.12 & 1.26 & 1.36 & 1.41 & 1.46 & 1.49 & 1.52 & 1.54 & 1.56 \\
\hline
\end{tabular}

When the order is greater than 2, the ratio of judgment matrix consistency index CI and the random consistency index RI with the same order is called random consistency, denoted as $\mathrm{CR}, C R=\frac{C I}{R I}$. When $\mathrm{CR}$ was $10 \%$, the consistency of judgment matrix is generally satisfied. And in some cases it can be relaxed to $20 \%$. But more than the ratio, it is necessary to adjust the consistency of the judgment matrix.

According to the importance of each factor in each level, each factor is given a corresponding weight value, which can be expressed as:

The first level, $A=\left\{a_{1}, a_{2}, \cdots, a_{n}\right\}$; the second level, $A_{i}=\left\{a_{i 1}, a i_{2}, \cdots, a_{i n}\right\}$; the weight coefficient are satisfied with $\sum_{i=1}^{4} a_{i j}=1$ and $\sum_{i=1}^{n} a_{i n} b_{i j}=1$.

\section{A Comprehensive Evaluation Model}

$\mathrm{U}$ is divided into two levels, after determining the comment set membership matrix of second level index, we synthesized fuzzy matrix to make single factor fuzzy evaluation for the goal in the first level. When the membership degree matrix of $\mathrm{v}$ to $\mathrm{U} 1, \mathrm{U} 2, \ldots, \mathrm{Un}$ is determined, and then the membership degree vector of the evaluation set can be determined.

(1) first level of fuzzy comprehensive evaluation

At first, the evaluation matrix $R_{i j}$ of each sub layer index is used as fuzzy matrix operation. $\mathrm{Bi}$ is the membership vector of Ui to V.

$$
B_{i}=A_{i} \bullet R_{i}=\left(a_{i 1}, a_{i 2} \cdots a_{i j}\right)\left[\begin{array}{l}
r_{i 11}, r_{i 12}, \cdots, r_{i 1 n} \\
r_{i 21}, r_{i 22}, \cdots, r_{i 2 n} \\
\vdots \\
r_{i j 1}, r_{i j 2}, \cdots, r_{i j n}
\end{array}\right]=\left(b_{i 1}, b_{i 2}, \cdots b_{i j}\right)
$$


(2) Second level of fuzzy comprehensive evaluation

Let $\mathrm{R}=[\mathrm{B} 1, \mathrm{~B} 2 \ldots \mathrm{Bn}] \mathrm{T}$, then make matrix operation for $\mathrm{R}$ to get membership vector of the target layer index $\mathrm{U}$ for the evaluation set $\mathrm{V}$.

$$
B=A \cdot R=\left(A_{1}, A_{2}, \cdots, A_{n}\right)\left[\begin{array}{l}
B_{1} \\
B_{2} \\
\vdots \\
B_{n}
\end{array}\right]=\left(b_{1}, b_{2}, \cdots, b_{n}\right)
$$

When $\sum_{j=1}^{n} b_{j} \neq 1$, we can use normalization processing to get $\bar{B}=\left(\overline{b_{1}}, \overline{b_{2}}, \cdots, \overline{b_{n}}\right)$. Final judgment result is $S=B C^{T}=\bar{B} C^{T}$.

\section{CASE ANALYSIS}

A production enterprise will outsource its transportation and distribution logistics to a third party logistics company. We try to make appraisal analysis for the company by fuzzy comprehensive evaluation method and determine whether it can be used as the ideal business partner.

\section{A. Evaluation Index}

According to Figure 1, the main factor is $\mathrm{U}=$ $\left\{\mathrm{U}_{1}, \mathrm{U}_{2}, \mathrm{U}_{3}, \mathrm{U}_{4}\right\}$. Define sub factor level indicator set as $U_{k}=\left\{U_{k 1}, U_{k 2}, U_{k 3}, U_{k 4}\right\}$.

\section{B. 3.2 Evaluation Level Set}

Evaluation grade is divided into 5 level, which is corresponding to 9.0 points or more (including 9.0 points), 8.0 points or more (including points and 8.0), 7.0 points or more (including 7.0 points), 6.0 points or more (including 6.0). In this way, we get $\mathrm{C}=(9.5,8.5,7.5,6.5,5.0)$.

\section{Evaluation of Membership Matrix}

The expert group is composed of 5 experts. They carry out a secret scoring for the evaluation indicators respectively, which is shown in Table 2.

TABLE II. SCORING OF EXPERTS

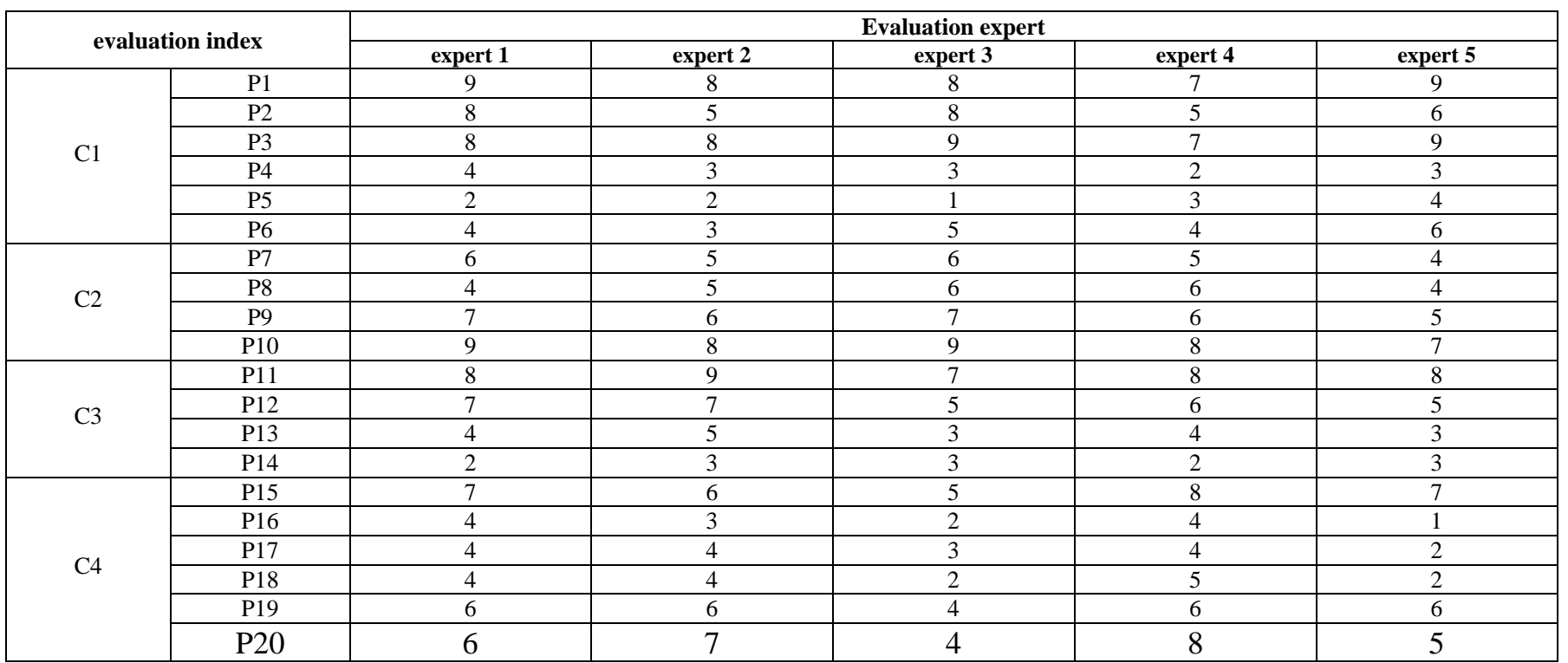

The data in Table 4 is compiled to get the membership matrix of sub factors $R_{i} \quad(\mathrm{i}=1,2,3,4)$. The membership

\begin{tabular}{|c|c|c|c|c|}
\hline $\mathrm{A}$ & $\mathrm{C} 1$ & $\mathrm{C} 2$ & $\mathrm{C} 3$ & $\mathrm{C} 4$ \\
\hline $\mathrm{C} 1$ & 1 & $1 / 3$ & $1 / 5$ & 3 \\
\hline $\mathrm{C} 2$ & 3 & 1 & $1 / 3$ & 5 \\
\hline $\mathrm{C} 3$ & 5 & 3 & 1 & 7 \\
\hline $\mathrm{C} 4$ & $1 / 3$ & $1 / 5$ & $1 / 7$ & 1 \\
\hline
\end{tabular}

matrix is as follows:

$$
R=\left[\begin{array}{l}
0.2141,0.1807,0.2061,0.1732,0.2259 \\
0.2129,0.1951,0.2264,0.2018,0.1638 \\
0.2085,0.2329,0.1725,0.1997,0.1864 \\
0.2139,0.2124,0.1429,0.2503,0.1786
\end{array}\right]
$$

\section{The Weight Set}

From the average value of the expert scoring, we can get judged matrix, as shown in Table 5.

TABLE III. EVALUATION JUDGMENT MATRIX OF LOGISTICS SERVICE PROVIDERS SELECTION

The characteristic value of the judgment matrix is calculated by the analytic hierarchy process:

$$
\begin{aligned}
& A=\left\{A_{1}, A_{2}, A_{3}, A_{4}\right\}=\left(\begin{array}{lll}
0.122 & 0.2630 .5580 .057
\end{array}\right) \\
& A_{1}=\left(\begin{array}{lll}
0.3960 .1810 .2230 .036 & 0.0680 .096
\end{array}\right) \\
& A_{2}=\left(\begin{array}{lll}
0.276 & 0.169 & 0.050 .505
\end{array}\right)
\end{aligned}
$$


$A_{3}=\left(\begin{array}{ll}0.5570 .2620 .1430 .038)\end{array}\right.$

$A_{4}=\left(\begin{array}{lll}0.3330 .0350 .0710 .0710 .1550 .333\end{array}\right)$

\section{E. Evaluation Results}

$A_{1}$ and $R_{1}$ are synthesized to get $B_{1} . \mathrm{B} 1=[0.2141$

$0.18070 .20610 .17320 .2259]$

In the same way, we get:

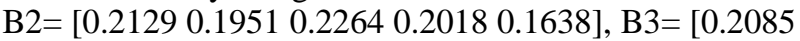

$0.23290 .17250 .19970 .1864]$

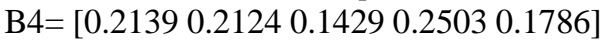

Based on $B_{1} 、 B_{2} 、 B_{3} 、 B_{4}$, we get R. A and R are synthesized to get $B=A \cdot R$.

$\mathrm{B}=\left[\begin{array}{l}0.21060 .21540 .18910 .19990 .1848\end{array}\right]$

Based on $\mathrm{C}=(9.5,8.5,7.5,6.5,5.0)$ and $\mathrm{B}$, we get $S=B C^{T}=\left(\begin{array}{lllll}0.2106 & 0.2154 & 0.1891 & 0.1999 & 0.1848\end{array}\right) \bullet$ $(9.5,8.5,7.5,6.5,5.0) \mathrm{T}=7.4432$.

It can be known that the logistics service provider is medium size, whose service capability is not strong. And it's not the ideal partner of the enterprise.

\section{CONCLUSION}

In order to make quantitative evaluation of ambiguous information more scientific and practical, fuzzy evaluation deals with object by digital means precisely. We can sort the objects according to the comprehensive score evaluated by this method. And it's possible to assess the object grade on the basis of fuzzy evaluation according to the maximum membership principle. It overcomes the defects of single result of the traditional mathematical method. This method is simple and feasible. It shows its application prospect on problems with fuzziness and uncertainty and it has been widely used in the fields of economy, management and so on.
However, with continuous application of comprehensive fuzzy evaluation in economy, management system, due to the complexity of the hierarchical structure, multi factor, uncertainty, insufficient information and of the fuzziness of human thinking contradictions, it's difficult to objectively make evaluation and decision-making. Fuzzy comprehensive evaluation synthesis algorithm also needs to be further explored.

\section{REFERENCE}

[1] Du Dong, Pang Qinghua, Wu Yan, "Modern comprehensive evaluation method and case analysis", Beijing: Tsinghua University Press, 2008.

[2] Lu-Ming Z, Yong B,'Status and Control Policy of Main Chronic Diseases in Community Health Management Bases in SHANGHAI and GUANGDONG", Medical Bulletin of Shanghai Jiaotong University, vol. 24, pp. 47 52, Feb. 2012.

[3] M. A. Khan, A Parveen, M. Sadiq, "a Method for the Selection of Software Development Life Cycle Models using Analytic Hierarchy Process". Issues and Challenges in Intelligent Computing Techniques (ICICT). Ghaziabad, 2014, IEEE Press, pp.535 540.

[4] Song H., Liu X., Lu A., et al, "Design and Development of Practical Course Experiment Management System". Computer Science \& Education (ICCSE), Colombo, 2013, IEEE Press, pp.1217 1220.

[5] Ren Y., Xing T., Xing Z., et al. "Application Research for Integrated $\mathrm{SSH}$ Combination Framework to Achieve MVC Mode", Computational and Information Sciences (ICCIS). Chengdu, China, 2011, IEEE Press, pp.499 502.

[6] Ye Y., "Reporting System Based on the University Project of the MVC Design Pattern", Computer Science \& Education (ICCSE), Colombo, 2013, IEEE Press, pp.931 935.

[7] Zhang H., Zhu S., "B/S implementation of Internet-based electrical engineering lab with MVC architecture", Control and Automation (ICCA). Hangzhou, China, 2013. IEEE Press, pp.551-555.

[8] Zhang D., Wei Z., Yang Y., "Research on Lightweight MVC Framework Based on spring and Mybatis", Computational Intelligence and Design, Hangzhou, China, 2013, pp.350-353. MVCIEEE. 